(C) 2005 American Chemical Society, J. Phys. Chem. A, Shkrob jp055500z, Supp. Info p. 1

\title{
Ammoniated electron as a solvent stabilized multimer radical anion.
}

Ilya A. Shkrob

Radiation and Photochemistry Group, Chemistry Division, Argonne National

Laboratory, 9700 South Cass Avenue, Argonne, Illinois 60439

Tel 630-2529516, FAX 630-2524993,e-mail: shkrob@anl.gov.

SUPPLEMENTARY MATERIAL JP055500z

Journal of Physical Chemistry A,

Received: September 27, 2005; Revised: January 18, 2006

\section{Supporting Information.}

(1.) The dimer, the trimer, and the tetramer ammonia anions.

\section{S.1. Dimer.}

The lowest energy B-type dimer anion 1 (Figure $1 \mathrm{~S}$, to the top) has $C_{2 h}$ symmetry; the D-type dimer anion 2 (Figure $1 \mathrm{~S}$, to the bottom) has $D_{3 d}$ symmetry and is ca. 150 meV more stable than anion 1 . Anion 1 is very tight (with $r\left(c-H_{a}\right) \approx 1.43 \AA$ vs. $2.9 \AA$ in anion 2) and, consequently, the spin density on $\mathrm{N}$ atoms is $50-70 \%$ greater than in medium size cluster anions. The $\mathrm{N}-\mathrm{H}$ bond lengths, however, are fairly close to those in the neutral molecule: 1.026 and $1.030 \AA$ in anion 1 and $1.026 \AA$ in anion 2 (Table $1 \mathrm{~S}$ ). The H-N-H angles are the smallest among all of the structures examined: $103-104^{\circ}$ in anion 1 and $102.4^{\circ}$ in anion 2. The Mulliken charge and spin densities on nitrogen atoms are large (-1.52 and 0.62 for anion 1 and -1.68 and 0.77 for anion 2 , respectively (Table 1S). Despite the large positive charge and spin density on $\mathrm{H}_{\mathrm{a}}$ protons in anion $1(+0.44$ and -0.088 , respectively) vs. anion $2(+0.37$ and -0.064 , respectively), the isotropic hfcc's on these protons are similar, -2.7 vs. $-2.4 \mathrm{G}$, and isotropic hfec's for ${ }^{14} \mathrm{~N}$ are also comparable, 27.7 vs. $22.9 \mathrm{G}$ (Table $1 \mathrm{~S}$ ). The anisotropic hyperfine coupling constants for the protons are ca. 2 times larger in anion 1 than in anion 2, as may be expected from the small size of anion 1. The tensors of anisotropic hyperfine interaction are approximately axial. The largest principal value $2 T$ is ca. $6 \mathrm{G}$ for ${ }^{1} \mathrm{H}$ in anion 1 vs. $3.3 \mathrm{G}$ in anion 2 (Table 1S). The anisotropy of hyperfine interaction for ${ }^{14} \mathrm{~N}$ nuclei is small in both of these dimer anions $\left(2 T_{N}<1.2 \mathrm{G}\right)$, and it further decreases with size in larger anions (Tables 1 and 1S). The total isotropic hfcc on ${ }^{14} \mathrm{~N}$ and ${ }^{1} \mathrm{H}$ nuclei are $55.4 \mathrm{G}$ and $-12 \mathrm{G}$ in anion $\mathbf{1}$ and $45.7 \mathrm{G}$ and $-14.4 \mathrm{G}$ in anion 2 , respectively. Notice that both the total atomic spin density and the isotropic hfcc's for the protons are negative. The charge density on the central ghost atom is fairly low ( -0.1 for 1 and -0.15 for 2$)$, i.e. the charge and spin

$1 \mathrm{~S}$. 
densities are mainly on the $\mathrm{N}$ atoms. Using more diffuse functions in the basis set does not change this partitioning appreciably.

In the calculated Raman spectrum of anion 1, the strongest bands are $3352 \mathrm{~cm}^{-1}$ $\left(\mathrm{B}_{\mathrm{u}}\right)$ and $3208 \mathrm{~cm}^{-1}\left(\mathrm{~A}_{\mathrm{g}}\right)$, there are also two weaker bands at 1635 and $3420 \mathrm{~cm}^{-1}$, both of which are $B_{\mathrm{g}}$ modes (Table 3 ). Thus, the asymmetric bend does not change and the stretch modes are strongly downshifted (Tables 2 and 3). While these dimer anions are poor reference models for $e_{a m}^{-}$, many of the features observed for these dimer anions are also observed for larger cluster anions.

\section{S.2. Trimer.}

The lowest energy B- and D- type trimer anions both have $C_{3 h}$ symmetry (anions 3 and 4 in Figure $2 \mathrm{~S}$, respectively); the former is ca. $160 \mathrm{meV}$ more energetic than the latter. The H-N-H angles are still rather small $\left(104^{\circ}\right.$ in anion 1 and $103^{\circ}$ in anion 2) and the N-H bonds are elongated (1.035 and 1.041 $\AA$ in anion $\mathbf{1}$ and $1.034 \AA$ in anion 2); see Table 1. The $\mathrm{c}-\mathrm{H}_{\mathrm{a}}$ distance increases, as compared to the dimer anions, to $1.9 \AA$ in anion 3 and $2.38 \AA$ in anion 4 . Though the spin is equally divided between the three nitrogens (rather than two nitrogens in anions 1 and 2), the total isotropic hfcc on ${ }^{14} \mathrm{~N}$ and ${ }^{1} \mathrm{H}$ nuclei is not too different from that in the dimer anions (Table $1 \mathrm{~S}$ ). The anisotropic hfcc for ${ }^{14} \mathrm{~N}$ are small $\left(2 T_{N}<1 \mathrm{G}\right)$ whereas those on the ${ }^{1} \mathrm{H}_{\mathrm{a}}$ nuclei are still relatively large $\left(2 T_{H} \approx 3.1\right.$ $\mathrm{G}$ for anion 3 and $4.5 \mathrm{G}$ for anion 4 ). The isotropic hfcc's on the protons are small (Table $1 \mathrm{~S})$ and the constants for ${ }^{14} \mathrm{~N}$ are large $(+20.7 \mathrm{G}$ for anion $\mathbf{3}$ and $+17.7 \mathrm{G}$ for anion 4$)$. While the geometry, spin and charge densities are sensitive to the choice of the basis set, especially when tight-binding sets (such as 4-31G and 6-31G) are used, the total hfec's on ${ }^{14} \mathrm{~N}$ and ${ }^{1} \mathrm{H}$ nuclei change only within $20 \%$. The main effect of tight-binding is to make the anion smaller; the partitioning of the excess electron density between the three nitrogen atoms and the "cavity" changes relatively little. The same applies to other ammonia anions.

\section{S.3. Tetramer.}

Both planar $C_{4 h}$ symmetrical clusters and "tetrahedral" $\left(D_{2 d}\right)$ clusters (analogous to those studied by Newton) ${ }^{45}$ were examined. The tightest of these clusters is a ring anion 5 shown in Figure 3S (top left), with extended hydrogen bonds (HN..H distance of $2.25 \AA$ ) between the monomers and $\mathrm{c}-\mathrm{H}_{\mathrm{a}}$ separation of only $1.88 \AA$ (Table $1 \mathrm{~S}$ ). This cluster is so tight that the positive spin density from the cavity-filling part of the wavefunction compensates the negative contribution due to the bond polarization, and the isotropic hfcc on $\mathrm{H}_{\mathrm{a}}$ is slightly positive, $+0.28 \mathrm{G}$. The resulting total isotropic hfcc on ${ }^{14} \mathrm{~N}$ and ${ }^{1} \mathrm{H}$ nuclei are $80.7 \mathrm{G}$ and $-2.2 \mathrm{G}$, respectively. In larger anions, all hfec on the protons are negative (Table 1S). Anion 5 is more energetic by ca. $125 \mathrm{meV}$ than star-shaped anion 6 (Figure 3S, top right), which, in turn, is more energetic by ca. $150 \mathrm{meV}$ than the $D_{2 d}$ symmetric anion 7 (Figure 6S, top). Isodensity HOMO maps for $C_{4 h}$ symmetric anions are shown in Figures $3 \mathrm{~S}$ (bottom right) and $4 \mathrm{~S}$ (both for anion 6) and Figure $5 \mathrm{~S}$ (for anion 8). D-type anion 8 (with $C_{4 h}$ symmetry; see Figure $3 \mathrm{~S}$, bottom left) and anion 9 (with $D_{2 d}$ symmetry; see Figure 6S, bottom) are isoenergetic and by ca. $100 \mathrm{meV}$ lower in 
energy than anion 7. The total isotropic hfcc on ${ }^{14} \mathrm{~N}$ is $+(50-65) \mathrm{G}$ (i.e., the average hfcc for ${ }^{14} \mathrm{~N}$ is $13-16 \mathrm{G}$ ) and that for the protons is between $-5.4 \mathrm{G}$ (for anion 6) and $-12.3 \mathrm{G}$ (for anion 9); see Table 1S. The latter parameter is systematically greater for D-type structures since there is no compensation of the negative hfcc constants (due to the interaction with the cavity electron) for inner $\mathrm{H}_{\mathrm{a}}$ protons in such anions. The anisotropic hyperfine interaction for ${ }^{14} \mathrm{~N}$ is weaker than in the dimer and trimer anions $\left(2 T_{N}<0.5\right.$ $0.7 \mathrm{G}$ ) and the protons are almost purely dipole coupled. Mulliken charge density on the $\mathrm{N}$ atoms is ca. -1.11 and the spin density is ca. $0.23-0.27$. While the $\mathrm{c}-\mathrm{H}_{\mathrm{a}}$ distances vary between $2.12 \AA$ (in anion 6) and 3.04 (in anion 9), the mean isotropic hfcc's on ${ }^{14} \mathrm{~N}$ and ${ }^{1} \mathrm{H}$ for these two tetramer anions are comparable (Table 1S) reflecting the fact that the spin density is divided mainly among the ammonia molecules. The spin density inside the cavity is relatively small and there is a node at the center, as seen from the isodensity HOMO maps shown in Figures $4 \mathrm{~S}$ through $7 \mathrm{~S}$. For all of the anions examined, most of the spin density is in the frontier orbitals of $N$ atoms.

For comparison to B-type dimer anion 1, it is instructive to examine vibration modes in B-type anion 6. The calculated Raman spectrum is dominated by the three $B_{g}$ bands at 1080,1629 , and $3201 \mathrm{~cm}^{-1}$ that correspond to $v_{2}, v_{4}$, and $v_{1}$ modes of the neutral ammonia (Table 3). Once more, the asymmetric bend is relatively unchanged and the symmetric stretch is downshifted by ca. $170 \mathrm{~cm}^{-1}$. For D-type anion $\mathbf{8}$, the two most prominent Raman modes are at 1633 and $3248 \mathrm{~cm}^{-1}$. The looser is the anion, the closer are the vibration frequencies to those of a neutral ammonia molecule. 


\section{(2). Figure captions (1S to 11S).}

\section{Fig. 1S}

B-type dimer anion 1 (the $C_{2 h}$ symmetry; to the top) and D-type dimer anion 2 (the $D_{3 d}$ symmetry; to the bottom); "c" is the inversion center. The two groups of magnetically equivalent protons are designated $H_{a}$ (inner protons) and $H_{b}$ (outer protons). Here and in other figures, the structures given have the lowest energy in the BLYP/6-31+G** density functional model. The structural and magnetic parameters for ${ }^{14} \mathrm{~N}$ and ${ }^{1} \mathrm{H}$ nuclei for these anions are given in Table $1 \mathrm{~S}$.

\section{Fig. 2S}

Optimized geometry for the $C_{3 h}$ symmetrical B-type trimer anion 3 (to the top) and Dtype trimer anion 4 (to the bottom). The dashed lines point from the center of mass "c" towards $\mathrm{H}_{\mathrm{a}}$ protons (highlighted for anion 4).

\section{Fig. 3S}

Optimized geometry $C_{4 h}$ symmetrical tetramer anions. To the top: Ring anion $\mathbf{5}$ (with hydrogen $\mathrm{HN}$... H bonds between the monomers; to the left) and star-shaped B-type anion 6 (to the right). To the bottom: D-type anion 8 (to the left) and in-plane and out-of-plane surface density maps for singly occupied HOMO of anion 6 (to the right). The deep blue corresponds to $-0.02 \mathrm{e} \AA^{-3}$, the deep red corresponds to $+0.02 \mathrm{e} \AA^{-3}$.

\section{Fig. 4S}

Isodensity surfaces for singly occupied HOMO of B-type tetramer anion 6. Scarlet is for positive density, violet is for negative density. The surfaces correspond to (a) \pm 0.01 , (b) \pm 0.02 , (c) \pm 0.03 , and (d) \pm 0.04 e $\AA^{-3}$. The cross marks the center of mass. Most of the spin density is in the frontier orbitals of $N$ atoms; the diffuse positive wavefunction that envelops the anion has a node at the center.

\section{Fig. 5S.}

The same as Fig. $4 \mathrm{~S}$, for $C_{4 h}$ symmetrical D-type tetramer anion $\mathbf{8}$.

\section{Fig. 6S}

Optimized geometry $D_{2 d}$ symmetrical tetramer anions. To the top: B-type anion 7 (top) and D-type anion 9 (bottom).

\section{Fig. 7S.}


The same as Fig. $4 \mathrm{~S}$, for $D_{2 d}$ symmetrical B-type tetramer anion 7 . The surfaces are

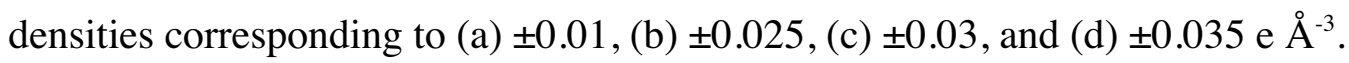

\section{Fig. 8S.}

The same as Fig. 7S, for $C_{i}$ symmetrical B-type hexamer anion $\mathbf{1 0}$.

\section{Fig. 9S.}

One of the hexamer anions with a broken-symmetry loose octahedral pattern. Some ammonia molecules are B-oriented, some are D-oriented. Despite the absence of order, the total hfcc's on ${ }^{14} \mathrm{~N}$ and ${ }^{1} \mathrm{H}$ nuclei show relatively little variation in such loose clusters.

\section{Fig. 10S.}

The same as Fig. 8S for "octahedral" hexamer anions modeled using (a) MP2 and (b) BLYP methods with $6-31++\mathrm{G}^{* *}$ basis set (a chlorine ghost atom was placed at the center). Isodensity contour maps of SOMO for optimized geometry hexamer anions are shown. The densities are, from top to bottom: (a) $\pm 0.017, \pm 0.02, \pm 0.03$, and \pm 0.0335 , and

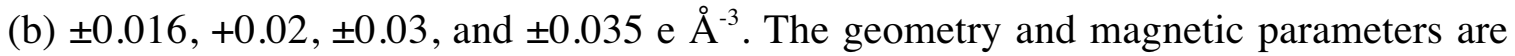
given in Table $3 \mathrm{~S}$.

\section{Fig. 11S.}

Signs for isotropic hfcc's on the protons of ammonia molecules in 18-mer radical anion shown in Figs. 4 and 5. 


\section{(3.) Table 1S.}

Geometry, atomic spin and charge densities, and magnetic parameters for model $\mathrm{am}_{n}^{-}$ cluster anions, $n=2-4(\mathrm{BLYP} / 6-31 \mathrm{G}+* *)$.

\begin{tabular}{|c|c|c|c|c|c|c|c|c|c|}
\hline anion, $a m_{n}^{-}$ & $\mathbf{1}$ & $\mathbf{2}$ & $\mathbf{3}$ & $\mathbf{4}$ & $\mathbf{5}$ & $\mathbf{6}$ & $\mathbf{7}$ & $\mathbf{8}$ & $\mathbf{9}$ \\
\hline$n ;$ type & $2, \mathrm{~B}$ & $2, \mathrm{D}$ & $3, \mathrm{~B}$ & $3, \mathrm{D}$ & $4, \mathrm{ring}$ & $4, \mathrm{~B}$ & $4, \mathrm{~B}$ & $4, \mathrm{D}$ & $4, \mathrm{D}$ \\
\hline symmetry & $C_{2 h}$ & $D_{3 d}$ & $C_{3 h}$ & $C_{3 h}$ & $C_{4 h}$ & $C_{4 h}$ & $D_{2 d}$ & $C_{4 h}$ & $D_{2 d}$ \\
\hline $\mathrm{r}\left(\mathrm{c}-\mathrm{H}_{\mathrm{a}}\right)$ & 1.436 & 2.189 & 1.903 & 2.378 & 1.88 & 2.358 & 2.122 & 2.774 & 3.136 \\
\hline $\mathrm{r}(\mathrm{c}-\mathrm{N})$ & 2.471 & 2.432 & 2.944 & 2.876 & 2.317 & 3.396 & 3.16 & 3.417 & 3.368 \\
\hline $\mathrm{r}\left(\mathrm{N}-\mathrm{H}_{\mathrm{a}}\right)$ & 1.034 & 1.026 & 1.041 & 1.037 & 1.043 & 1.038 & 1.038 & 1.035 & 1.031 \\
\hline $\mathrm{r}\left(\mathrm{N}-\mathrm{H}_{\mathrm{b}}\right)$ & 1.026 & 1.026 & 1.035 & 1.034 & 1.032 & 1.032 & 1.031 & 1.032 & 1.033 \\
\hline $\mathrm{a}\left(\mathrm{H}_{\mathrm{a}}-\mathrm{c}-\mathrm{N}\right)$ & 0 & 24.9 & 0 & 20 & 26.2 & 0 & 0 & 15.2 & 17.8 \\
\hline $\mathrm{a}\left(\mathrm{H}_{\mathrm{a}}-\mathrm{N}-\mathrm{H}_{\mathrm{b}}\right)$ & 103 & 102.4 & 103.7 & 102.7 & 106.3 & 104.1 & 104.4 & 103.9 & 103.6 \\
\hline $\mathrm{a}\left(\mathrm{H}_{\mathrm{b}}-\mathrm{N}-\mathrm{H}_{\mathrm{b}}\right)$ & 103.8 & 102.4 & 104.2 & 102.8 & 104.8 & 104.5 & 105.3 & 103.9 & 103.1 \\
\hline $\mathrm{d}\left(\mathrm{c}-\mathrm{H}_{\mathrm{a}}-\mathrm{N}-\mathrm{H}_{\mathrm{b}}\right)$ & 53.9 & 53 & 125.6 & 53.2 & 124.4 & 125.4 & 124.9 & 54.2 & 53.7 \\
\hline $\mathrm{A}\left({ }^{14} \mathrm{~N}\right)$ & 27.7 & 22.9 & 20.7 & 17.7 & 20.2 & 16 & 14.5 & 13.5 & 12.8 \\
\hline$-\mathrm{A}\left({ }^{1} \mathrm{H}_{\mathrm{a}}\right)$ & 2.7 & 2.4 & 0.85 & 1.3 & -0.28 & 0.77 & 0.91 & 0.99 & $0.91^{\mathrm{a}}$ \\
\hline$-\mathrm{A}\left({ }^{1} \mathrm{H}_{\mathrm{b}}\right)$ & 1.65 & 2.4 & 0.55 & 1.35 & 0.41 & 0.29 & $0.52^{\mathrm{a}}$ & 0.95 & $1.09^{\mathrm{a}}$ \\
\hline$\Sigma_{\mathrm{N}} \mathrm{A}$ & 55.4 & 45.7 & 62.1 & 53.1 & 80.7 & 64 & 58.2 & 11.6 & 51.3 \\
\hline$-\Sigma_{\mathrm{H}} \mathrm{A}$ & 12 & 14.4 & 11.7 & 12 & 2.17 & 5.4 & 7.8 & 11.6 & 12.3 \\
\hline $2 \mathrm{~T}\left({ }^{14} \mathrm{~N}\right)$ & 1.05 & 1.24 & 0.75 & 1.0 & 0.1 & 0.5 & 0.7 & 0.8 & 0.78 \\
\hline $2 \mathrm{~T}\left({ }^{1} \mathrm{H}_{\mathrm{a}}\right)$ & 6.1 & 3.3 & 4.5 & 3.1 & 1.03 & 3.4 & 3.75 & 2.7 & 1.64 \\
\hline $2 \mathrm{~T}\left({ }^{1} \mathrm{H}_{\mathrm{b}}\right)$ & 8.6 & 3.3 & 2.1 & 2.3 & 1.42 & 1.5 & 1.7 & 1.7 & 2.2 \\
\hline$-\rho_{\mathrm{c}}(\mathrm{N})$ & 1.52 & 1.68 & 1.23 & 1.32 & 1.23 & 1.1 & 1.12 & 1.17 & 1.17 \\
\hline$\rho_{\mathrm{c}}\left(\mathrm{H}_{\mathrm{a}}\right)$ & 0.44 & 0.37 & 0.35 & 0.33 & 0.42 & 0.31 & 0.32 & 0.32 & 0.3 \\
\hline$\rho_{\mathrm{c}}\left(\mathrm{H}_{\mathrm{b}}\right)$ & 0.31 & 0.37 & 0.29 & 0.32 & 0.28 & 0.285 & 0.28 & 0.30 & 0.31 \\
\hline$\rho_{\mathrm{s}}(\mathrm{N})$ & 0.62 & 0.77 & 0.35 & 0.43 & 0.30 & 0.23 & 0.24 & 0.28 & 0.29 \\
\hline$\rho_{\mathrm{s}}\left(\mathrm{H}_{\mathrm{a}}\right), \mathrm{x} 100$ & -8.7 & -6.4 & -1.2 & -2 & -3 & 1 & 0.7 & -0.95 & -1.3 \\
\hline$\rho_{\mathrm{s}}\left(\mathrm{H}_{\mathrm{b}}\right), \mathrm{x} 100$ & -4 & -6.4 & -1.5 & -2.5 & -1.2 & -0.8 & 0.75 & -1.2 & -1 \\
\hline
\end{tabular}

Bond distances (r) are in $\AA$, bond (a) and dihedral (d) angles in ${ }^{\circ}$, isotropic hfcc's (A) for the given nuclei, sum total isotropic hfcc $(\Sigma A)$ for ${ }^{14} \mathrm{~N}$ and ${ }^{1} \mathrm{H}$ and maximum principal values of the tensor for anisotropic hyperfine interaction (2T) in Gauss, Mulliken atomic spin $\left(\rho_{\mathrm{s}}\right)$ and charge $\left(\rho_{\mathrm{c}}\right)$ densities in e $\AA^{-3}$. Symbol "c" stands for the cavity center; $n$ is the number of ammonia molecules; $B$ is for bond- and D- is for dipole oriented cluster anions. (a) average value. 


\section{(4). Table 2S.}

Geometry, atomic spin and charge densities, and magnetic parameters for B-type $\mathrm{am}_{6}^{-}$ cluster anions as a function of $\mathrm{c}-\mathrm{H}_{\mathrm{a}}$ distance (BLYP/6-31G+**).

\begin{tabular}{|c|c|c|c|c|c|c|c|c|c|}
\hline $\mathrm{r}\left(\mathrm{c}-\mathrm{H}_{\mathrm{a}}\right)$ & 2.0 & 2.1 & 2.2 & 2.3 & 2.4 & 2.5 & 2.6 & 2.8 & 3.0 \\
\hline $\mathrm{r}\left(\mathrm{N}-\mathrm{H}_{\mathrm{a}}\right)$ & 1.039 & 1.038 & 1.037 & 1.036 & 1.035 & 1.034 & 1.033 & 1.032 & 1.031 \\
\hline $\mathrm{d}\left(\mathrm{c}-\mathrm{H}_{\mathrm{a}}-\mathrm{N}-\mathrm{H}_{\mathrm{b}}\right)$ & 124.6 & 124.5 & 124.5 & 124.4 & 124.4 & 124.4 & 124.4 & 124.4 & 124.4 \\
\hline $\mathrm{A}\left({ }^{14} \mathrm{~N}\right)$ & 13.0 & 12.3 & 11.8 & 11.2 & 10.7 & 10.3 & 9.85 & 9.2 & 8.7 \\
\hline$-\mathrm{A}\left({ }^{1} \mathrm{H}_{\mathrm{a}}\right)$ & 1.01 & 0.93 & 0.86 & 0.8 & 0.75 & 0.71 & 0.68 & 0.65 & 0.65 \\
\hline$-\mathrm{A}\left({ }^{1} \mathrm{H}_{\mathrm{b}}\right)$ & 0.197 & 0.2 & 0.19 & 0.18 & 0.18 & 0.18 & 0.19 & 0.2 & 0.21 \\
\hline$\Sigma_{\mathrm{N}} \mathrm{A}$ & 77.9 & 74 & 70.5 & 67.2 & 64.2 & 61.5 & 59.1 & 55.1 & 52.3 \\
\hline$-\Sigma_{\mathrm{H}} \mathrm{A}$ & 8.4 & 7.8 & 7.3 & 6.9 & 6.6 & 6.4 & 6.3 & 6.3 & 6.4 \\
\hline $2 \mathrm{~T}\left({ }^{14} \mathrm{~N}\right)$ & 0.65 & 0.58 & 0.53 & 0.49 & 0.45 & 0.44 & 0.37 & 0.33 & 0.31 \\
\hline $2 \mathrm{~T}\left({ }^{1} \mathrm{H}_{\mathrm{a}}\right)$ & 4.3 & 3.9 & 3.6 & 3.3 & 2.8 & 2.6 & 2.4 & 2.0 & 1.74 \\
\hline $2 \mathrm{~T}\left({ }^{1} \mathrm{H}_{\mathrm{b}}\right)$ & 1.5 & 1.4 & 1.3 & 1.2 & 1.1 & 1.0 & 1.0 & 0.85 & 0.73 \\
\hline$-\rho_{\mathrm{c}}(\mathrm{N})$ & 0.98 & 0.98 & 0.99 & 0.99 & 1.0 & 1.0 & 1.01 & 1.02 & 1.03 \\
\hline$\rho_{\mathrm{c}}\left(\mathrm{H}_{\mathrm{a}}\right)$ & 0.287 & 0.283 & 0.286 & 0.288 & 0.291 & 0.294 & 0.297 & 0.303 & 0.308 \\
\hline$\rho_{\mathrm{s}}(\mathrm{N}), \mathrm{x} 10$ & 1.04 & 1.07 & 1.1 & 1.17 & 1.23 & 1.29 & 1.35 & 1.47 & 1.6 \\
\hline$\rho_{\mathrm{s}}\left(\mathrm{H}_{\mathrm{a}}\right), \mathrm{x} 10^{2}$ & 3.6 & 3.5 & 3.3 & 3.07 & 2.75 & 2.4 & 2.0 & 1.3 & 0.53 \\
\hline$\rho_{\mathrm{s}}\left(\mathrm{H}_{\mathrm{b}}\right), \mathrm{x} 10^{3}$ & 2.8 & 2.0 & 1.3 & 0.4 & -0.5 & -1.3 & -2.2 & -3.9 & -5.5 \\
\hline$\Delta E, \mathrm{meV}$ & 93 & 53 & 26 & 10 & 4 & 6 & 17 & 57 & 119 \\
\hline
\end{tabular}

See the legend for Table 1S for units and notations used. $\Delta E$ is the energy relative to the optimized anion. $\mathrm{a}\left(\mathrm{H}_{\mathrm{a}}-\mathrm{N}-\mathrm{H}_{\mathrm{b}}\right)$ is ca. $104.8^{0}, \mathrm{r}\left(\mathrm{N}-\mathrm{H}_{\mathrm{b}}\right)$ is ca. $1.03 \AA$, and $\rho_{\mathrm{c}}\left(\mathrm{H}_{\mathrm{b}}\right)$ is ca. $0.28 \mathrm{e}$ $\AA^{-3}$ for all of these structures. Mean isotropic and anisotropic hfcc's for ${ }^{14} \mathrm{~N}$ and ${ }^{1} \mathrm{H}$ nuclei are in Gauss $\left(1 \mathrm{G}=10^{-4} \mathrm{~T}\right)$. 
(C) 2005 American Chemical Society, J. Phys. Chem. A, Shkrob jp055500z, Supp. Info p. 8

(5.) Table 3S.

Geometry, atomic spin and charge densities, and magnetic parameters for $C_{i}$ symmetrical B-type ("octahedral") ammonia anions.

\begin{tabular}{|c|c|c|c|c|}
\hline method & BLYP & MP2 & BLYP & MP2 \\
\hline $\begin{array}{c}\text { basis set for } \\
\text { optimization }\end{array}$ & $6-31+\mathrm{G}^{*}$ & $6-31+\mathrm{G}^{*}$ & $6-31++\mathrm{G}^{* *}$ & $6-31++\mathrm{G}^{* *}$ \\
\hline $\mathrm{r}\left(\mathrm{c}-\mathrm{H}_{\mathrm{a}}\right)$ & 2.418 & 2.370 & 2.501 & 2.333 \\
\hline $\mathrm{r}(\mathrm{c}-\mathrm{N})$ & 3.452 & 3.390 & 3.533 & 3.351 \\
\hline $\mathrm{r}\left(\mathrm{N}-\mathrm{H}_{\mathrm{b}}\right)$ & 1.030 & 1.015 & 1.030 & 1.016 \\
\hline $\mathrm{a}\left(\mathrm{H}_{\mathrm{a}}-\mathrm{N}-\mathrm{H}_{\mathrm{b}}\right)$ & 104.9 & 105.5 & 105.5 & 105.9 \\
\hline $\mathrm{d}\left(\mathrm{c}-\mathrm{H}_{\mathrm{a}}-\mathrm{N}-\mathrm{H}_{\mathrm{b}}\right)$ & 124.4 & 123.8 & 123.9 & 123.4 \\
\hline $\mathrm{A}\left({ }^{14} \mathrm{~N}\right)$ & $10.6\left(8.0^{\mathrm{b}}, 9.4^{\mathrm{c}}\right)$ & $7.2\left(11.9^{\mathrm{a}}, 9.6^{\mathrm{c}}\right)$ & $7.8\left(9.2^{\mathrm{c}}\right)$ & $5.1\left(8.4^{\mathrm{b}}, 8.55^{\mathrm{c}}\right)$ \\
\hline$-\mathrm{A}\left({ }^{1} \mathrm{H}_{\mathrm{a}}\right)$ & $0.74\left(0.31^{\mathrm{b}}\right.$, & $4.8\left(0.92^{\mathrm{a}}, 0.4^{\mathrm{c}}\right)$ & $0.39\left(0.38^{\mathrm{c}}\right)$ & $2.2\left(0.4^{\mathrm{b}}, 0.47^{\mathrm{c}}\right)$ \\
& $\left.0.42^{\mathrm{c}}\right)$ & & & $0.66\left(0.04^{\mathrm{b}}\right.$, \\
\hline$-\mathrm{A}\left({ }^{1} \mathrm{H}_{\mathrm{c}}\right)$ & $0.18\left(0.05^{\mathrm{b}}\right.$, & $0.92\left(0.21^{\mathrm{a}}\right.$, & $0.08\left(0.05^{\mathrm{c}}\right)$ & $\left.\approx 0^{\mathrm{c}}\right)$ \\
\hline$\Sigma_{\mathrm{N}} \mathrm{A}$ & $\left.0.03^{\mathrm{c}}\right)$ & $\left.0.02^{\mathrm{c}}\right)$ & & $30.8\left(50.5^{\mathrm{b}}\right.$, \\
& $63.8\left(48.2^{\mathrm{b}}\right.$, & $43\left(71.3^{\mathrm{a}}\right.$, & $46.7\left(55.1^{\mathrm{c}}\right)$ & $\left.59.1^{\mathrm{c}}\right)$ \\
\hline$-\Sigma_{\mathrm{H}} \mathrm{A}$ & $\left.56.5^{\mathrm{c}}\right)$ & $\left.57.6^{\mathrm{c}}\right)$ & & $21.3\left(2.9^{\mathrm{b}}, 2.8^{\mathrm{c}}\right)$ \\
\hline $2 \mathrm{~T}\left({ }^{14} \mathrm{~N}\right)$ & $0.51\left(0.32^{\mathrm{b}}\right.$, & $0.5\left(0.51^{\mathrm{a}}, 0.4^{\mathrm{c}}\right)$ & $0.27\left(0.3^{\mathrm{c}}\right)$ & $0.17\left(0.37^{\mathrm{b}}\right.$, \\
& $\left.0.36^{\mathrm{c}}\right)$ & & & $\left.0.4^{\mathrm{c}}\right)$ \\
\hline $2 \mathrm{~T}\left({ }^{1} \mathrm{H}_{\mathrm{a}}\right)$ & $3.2\left(2.0^{\mathrm{b}}, 2.1^{\mathrm{c}}\right)$ & $4.0\left(2.75^{\mathrm{a}}, 2.0^{\mathrm{c}}\right)$ & $1.9\left(2.0^{\mathrm{c}}\right)$ & $1.8\left(1.9^{\mathrm{b}}, 2.2^{\mathrm{c}}\right)$ \\
\hline $2 \mathrm{~T}\left({ }^{1} \mathrm{H}_{\mathrm{c}}\right)$ & $1.3\left(0.9^{\mathrm{b}}, 1.2^{\mathrm{c}}\right)$ & $1.1\left(0.98^{\mathrm{a}}, 1.2^{\mathrm{c}}\right)$ & $0.8\left(1.1^{\mathrm{c}}\right)$ & $0.6\left(0.9^{\mathrm{b}}, 1.0^{\mathrm{c}}\right)$ \\
\hline
\end{tabular}

Bond distances (r) are in $\AA$, bond (a) and dihedral (d) angles are in ${ }^{\circ}$ (optimized geometry); average isotropic hfcc's (A) for the given nuclei, sum total isotropic hfcc $(\Sigma A)$ for ${ }^{14} \mathrm{~N}$ and ${ }^{1} \mathrm{H}$ and maximum principal values of the tensor for anisotropic hyperfine interaction (2T) are in Gauss. Symbol "c" stands for the cavity center (at which a ghost chlorine atom was placed). Calculated using BLYP method with (a) 6-31+G** double- $\zeta$ basis set; (b) 6-31++G** double- $\zeta$ basis set; (c) EPR-III triple- $\zeta$ basis set with improved $s$-part. For neutral $C_{3 v}$ symmetrical ammonia molecule, $\mathrm{r}(\mathrm{N}-\mathrm{H})=1.025$ and $1.012 \AA$ and $\mathrm{a}(\mathrm{H}-\mathrm{N}-\mathrm{H})=107.5^{\circ}$ and $108^{\circ}$, in the BLYP and MP2 models with $6-31++\mathrm{G}^{* *}$ basis set, respectively. 

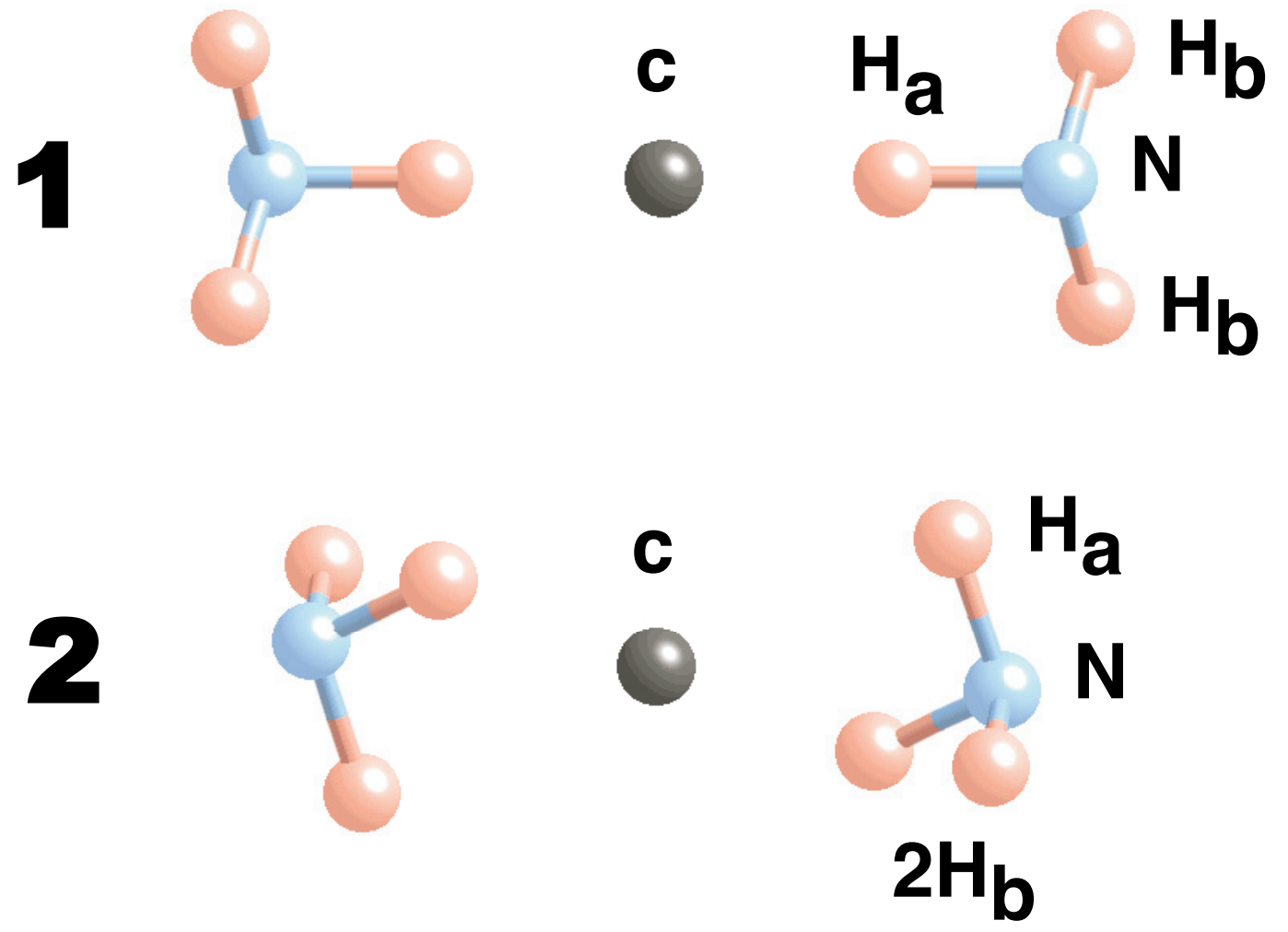

Figure 1S; Shkrob 


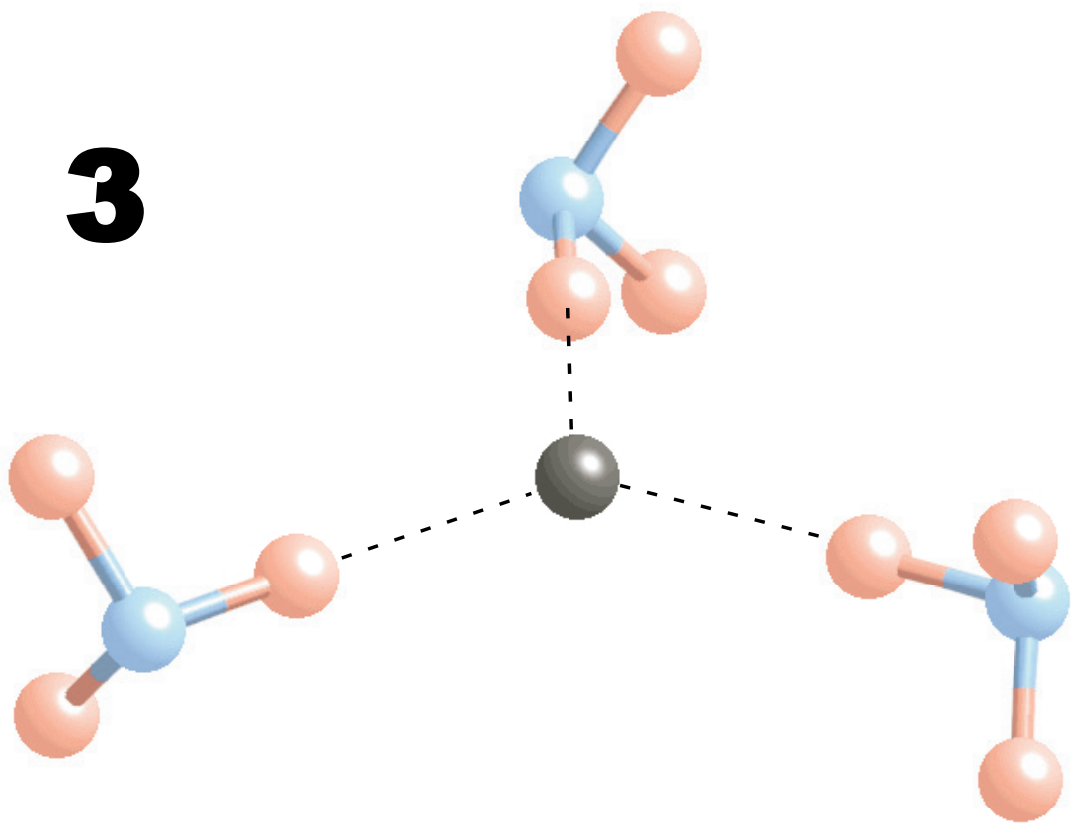

4

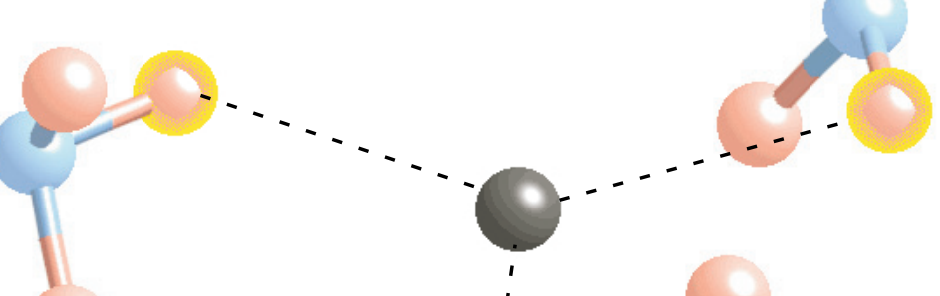

Figure 2S; Shkrob 
8

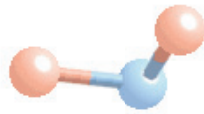

○

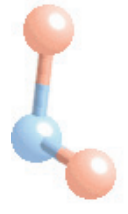

5

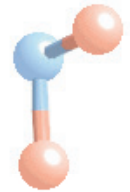

○

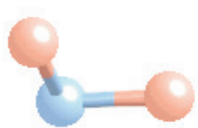

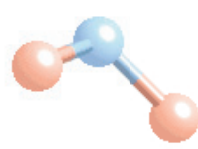

$\odot$
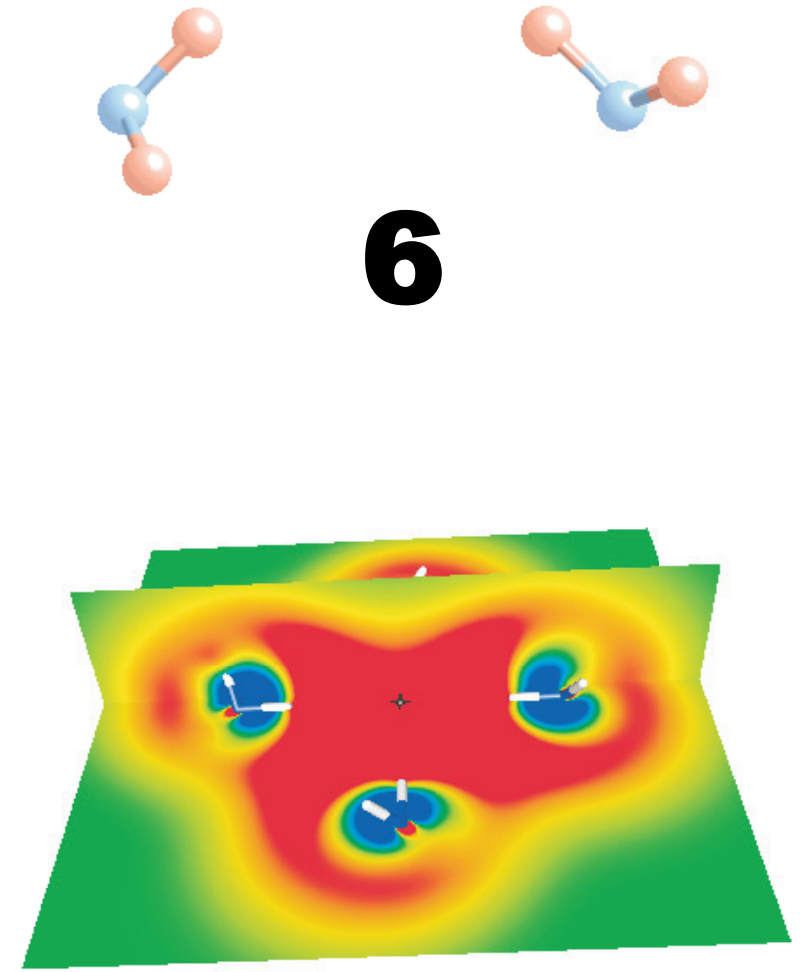

8

Figure 3S; Shkrob 
ANION 6

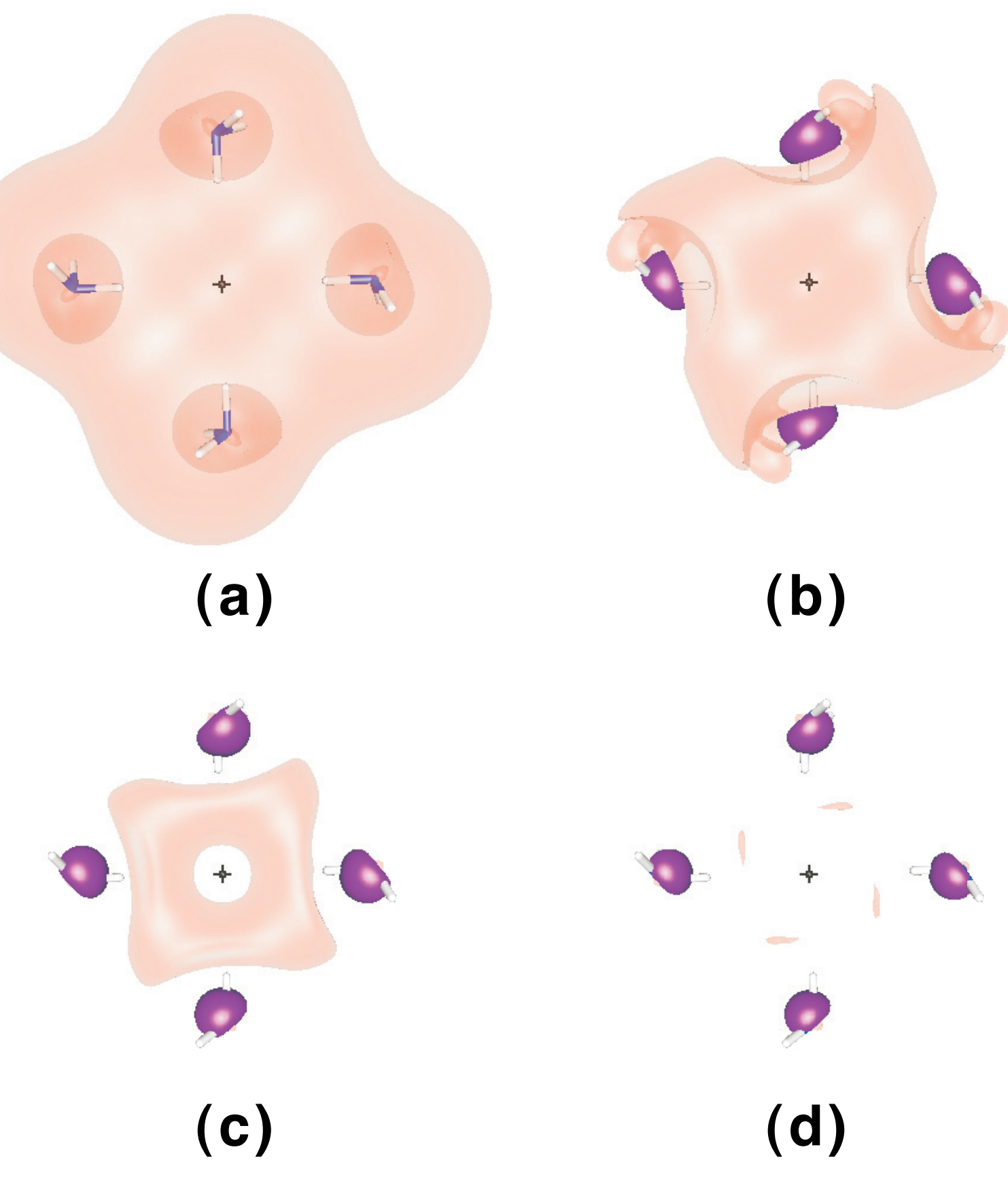

Figure 4S; Shkrob 
ANION 8

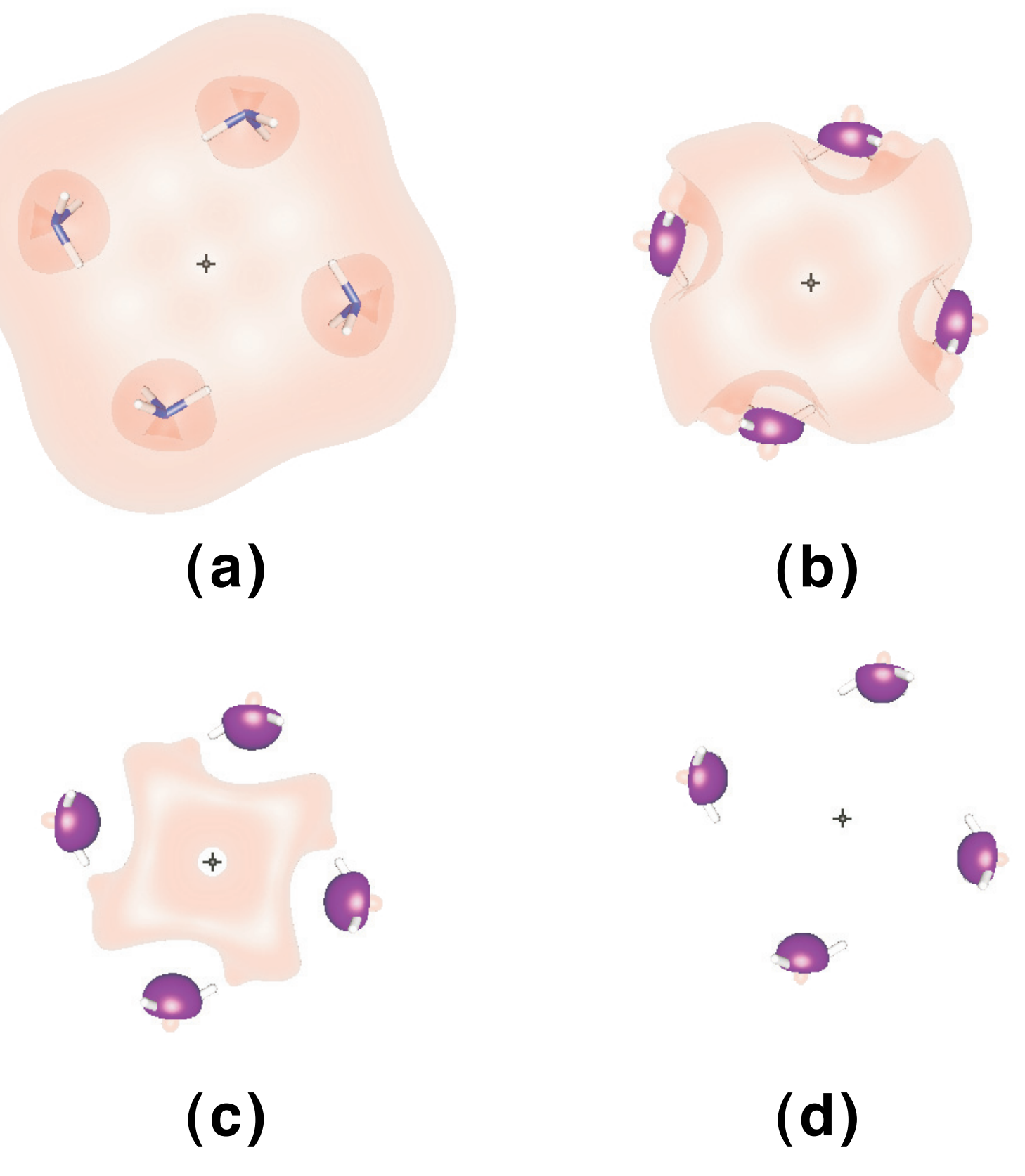

Figure 5S; Shkrob 


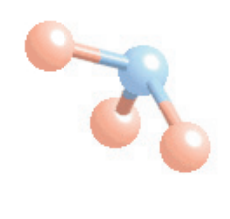

○
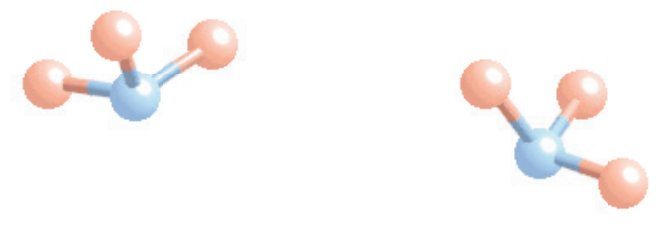

7
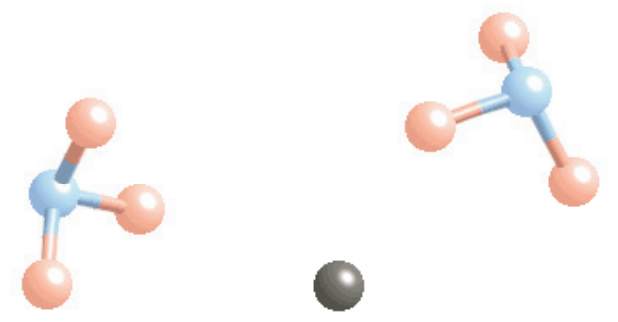

-
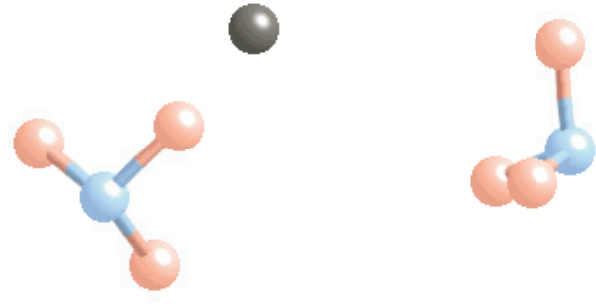

9

Figure 6S; Shkrob 


\section{ANION 7}

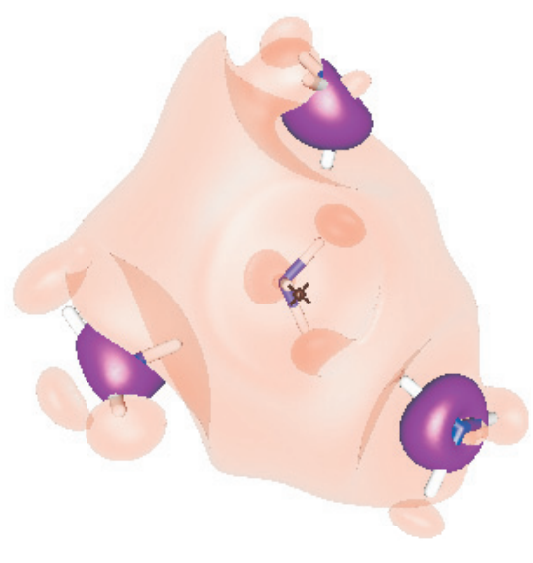

(a)

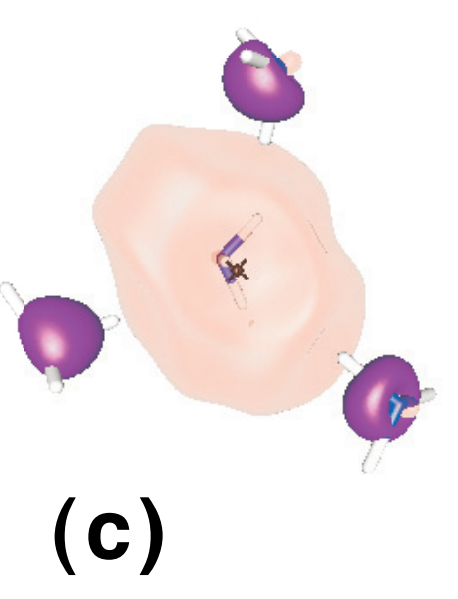

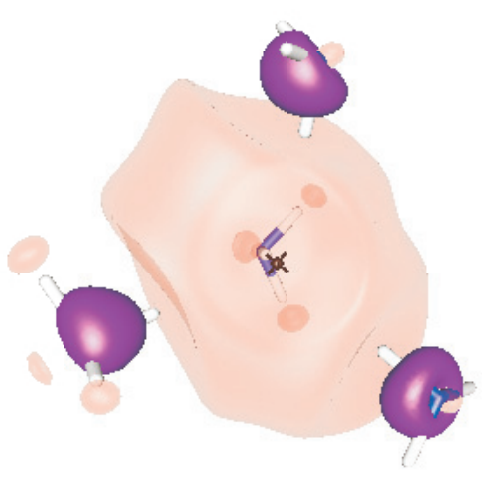

(b)

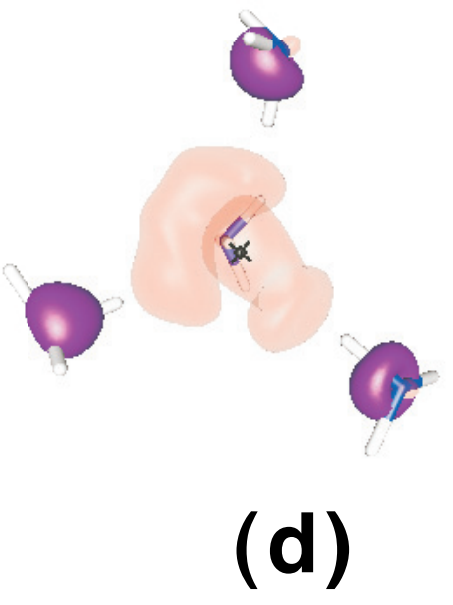

Figure 7S; Shkrob 


\section{ANION 10}
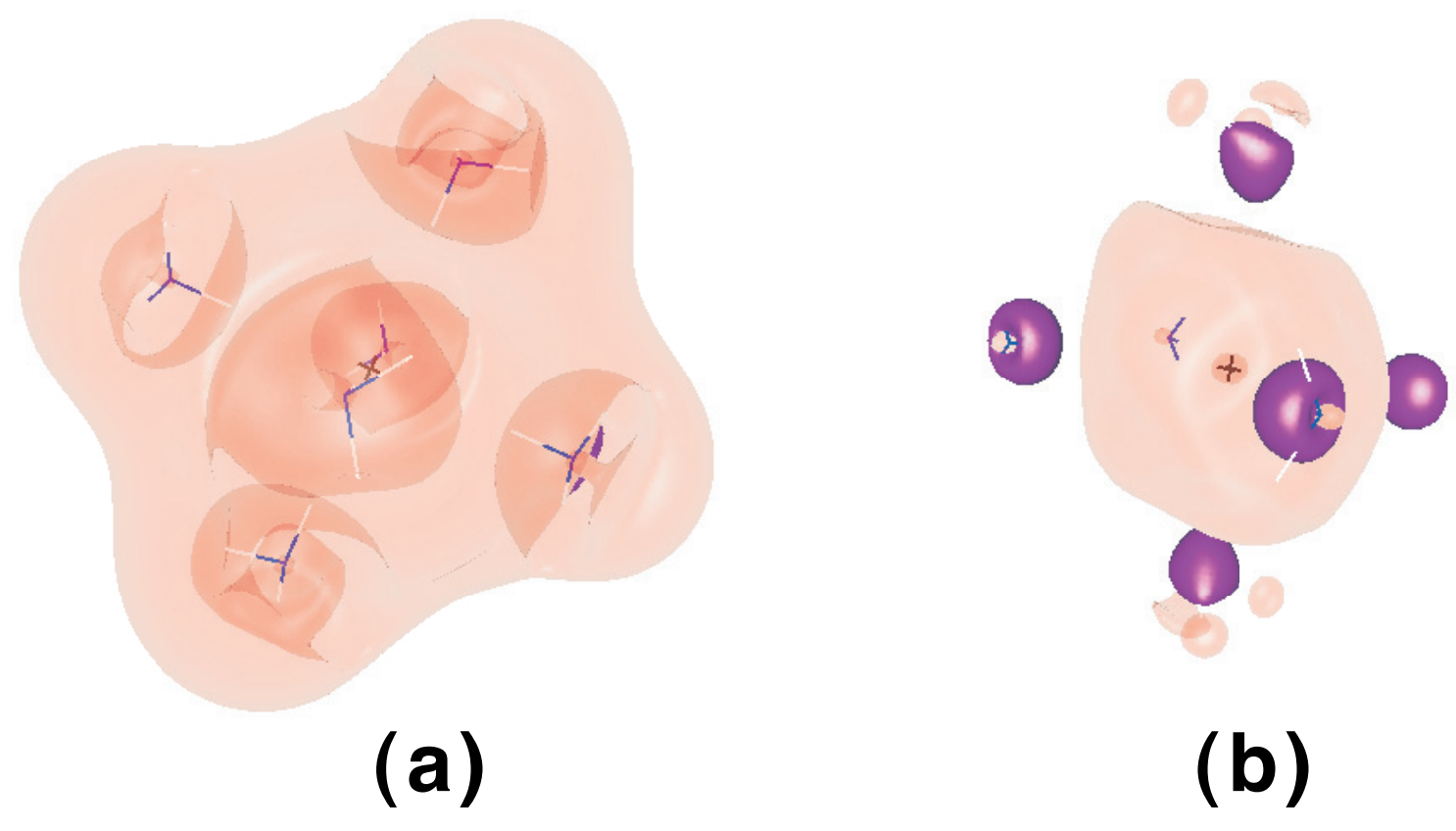

(b)
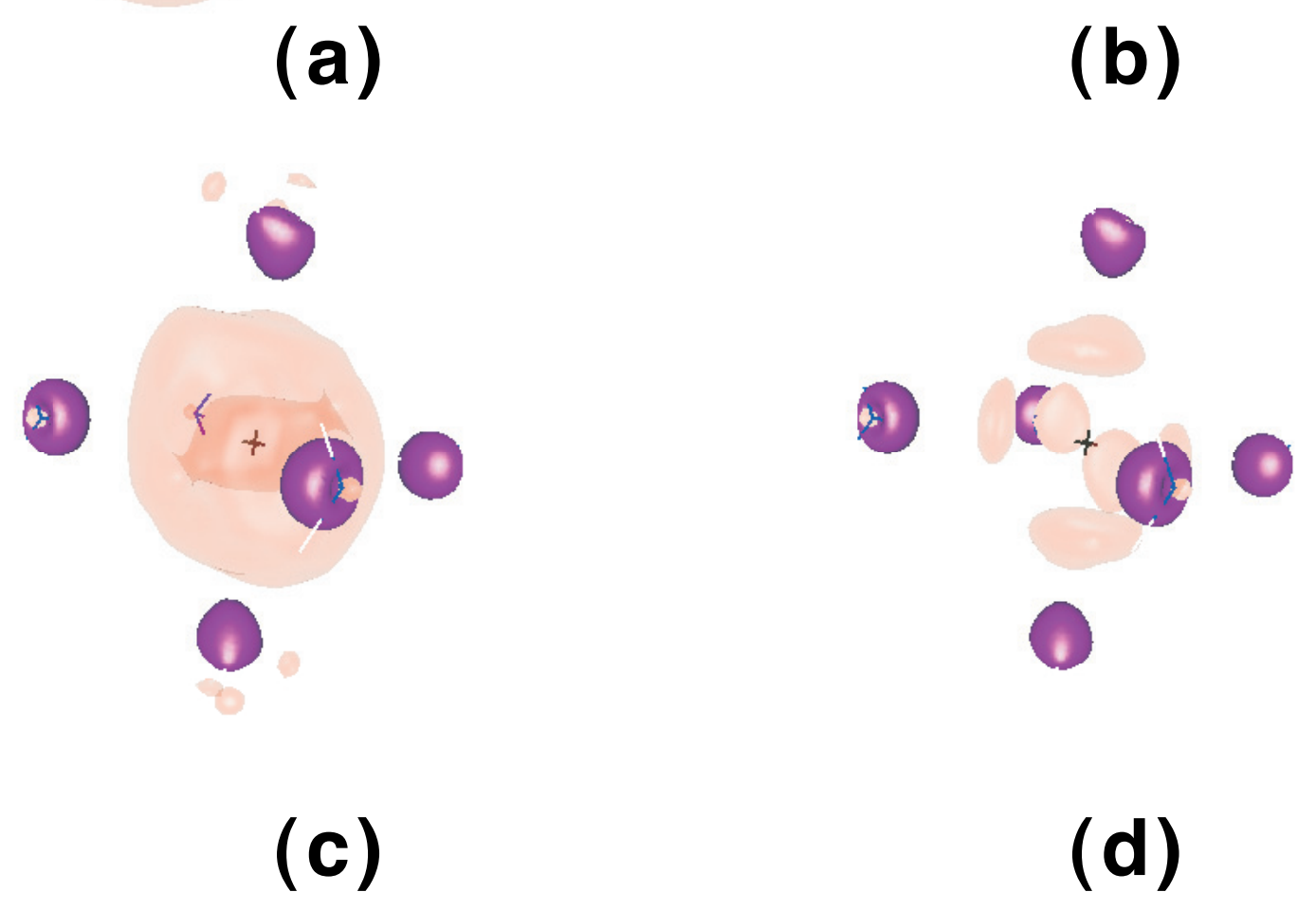

Figure 8S; Shkrob 


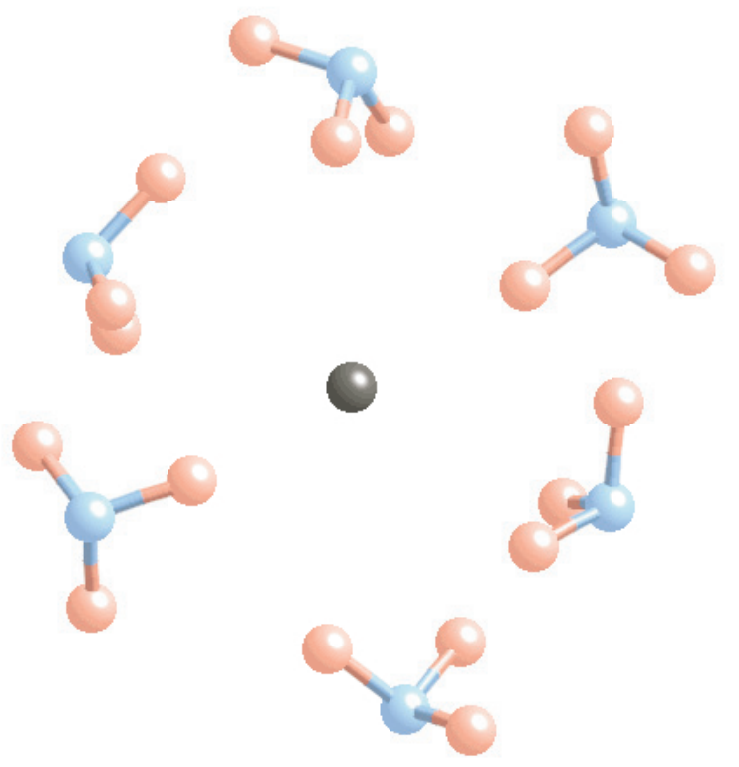

Figure 9S; Shkrob 
Figure 10S; Shkrob
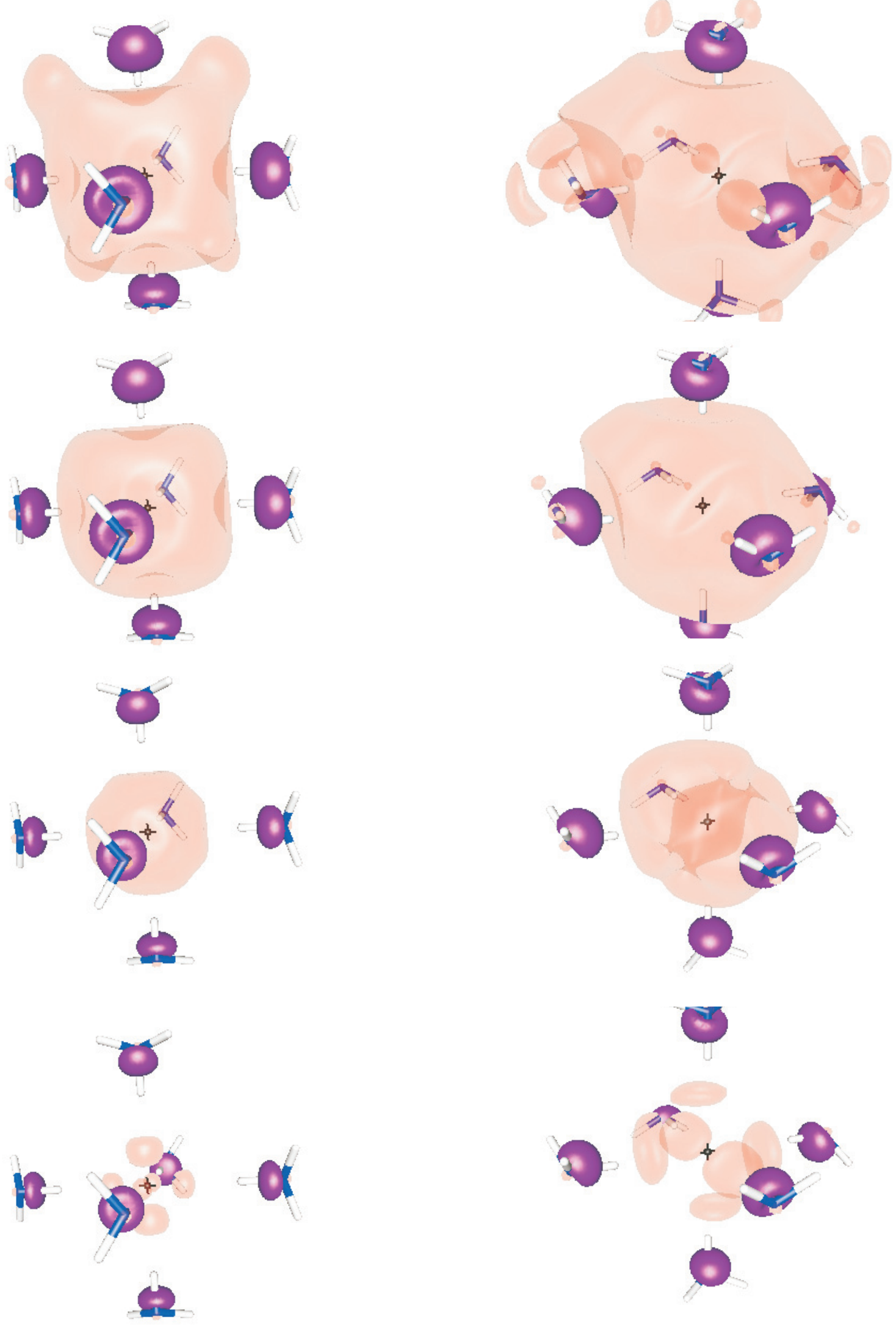

(a) MP2

(b) BLYP 


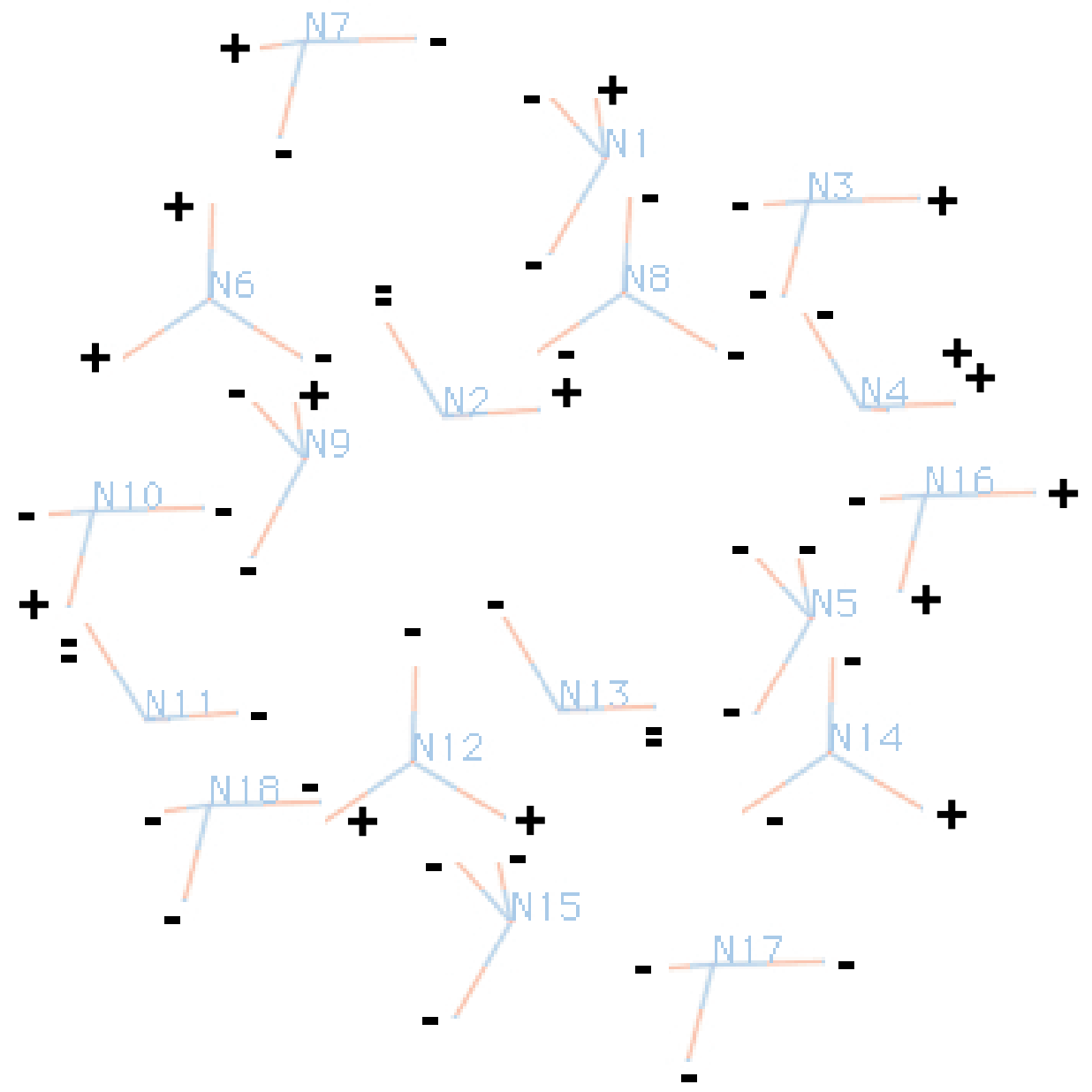

Figure 11S; Shkrob 